\title{
Pushing the limits of flash photolysis to unravel the secrets of biological electron and proton transfer
}

\author{
Paul Mathis $^{1} \cdot$ Evelyne Sage $^{2} \cdot$ Martin Byrdin $^{3}$
}

Accepted: 5 November 2021 / Published online: 26 January 2022

(c) The Author(s), under exclusive licence to European Photochemistry Association, European Society for Photobiology 2021, corrected publication 2022

\begin{abstract}
Time-resolved absorption spectroscopy is a powerful tool to unravel biological functions and has been a key technology for elucidating the working of electron transfer chains in photosynthesis or photorepair of UV-damaged DNA. Both of these areas have seen important contributions from laboratories all over the world, not the least of them stemming from the ingenious technical advances described by Klaus Brettel, first at the Technical University of Berlin (Germany), and later at the Atomic Energy Agency in Saclay (France). Now, after more than forty years of tireless scientific activity, Klaus is approaching retirement and this collection gathers together tributes in the form of scientific contributions from colleagues along the way, covering a spectrum of topics as diverse as photosynthesis, light-induced DNA repair, electron and proton transfer in light signalling, flavin based photo-enzymology, fluorescent marker photophysics, synthetic models and modelisation, delicate sample transient absorption spectroscopy. In an era where science is increasingly changing context from "fundamental" to "applied", Klaus' curiosity and tenacity worked hand in hand in a most effective manner to further both technical possibilities and basic understanding.
\end{abstract}

\section{Flash absorption spectroscopy started in 1949 (by PM)}

The technique of flash absorption spectroscopy was invented in 1949 by Ronald Norrish and George Porter, who were interested in rapid chemical reactions such as the explosive oxidation of hydrocarbons initiated by light $[1,2]$. They used a combination of flash photolysis and flash spectroscopy: a molecule of interest (such as $\mathrm{NO}_{2}, \mathrm{Cl}_{2}$ or $\mathrm{CS}_{2}$ ) was dissociated by a strong flash, and the reactive intermediates were detected by weaker monitoring flashes sent through the reaction vessel at variable times after the strong flash, permitting the recording of reaction kinetics. Their time resolution was as short as 20 microseconds. In 1967 they shared the Nobel Prize in chemistry for their invention.

Martin Byrdin

martin.byrdin@ibs.fr

1 Section de Bioénergétique, CEA Saclay, 91191 Gif-sur-Yvette, France

2 Centre de Recherche, CNRS UMR3347, Institut Curie, 91401 Orsay, France

3 Institut de Biologie Structurale, 38044 Grenoble, France
When I started working in CEA Saclay in 1964 with the objective of studying fast reactions in photosynthesis, two groups were already active in the field, that of Bacon Ke in Yellow Springs, Ohio, and especially that of Horst T. Witt in Berlin [3, 4]. Witt's group had made detailed studies of a large number of light-induced signals in chloroplasts (results brought together and updated in [5]). Their most successful study, in my opinion, concerned the pigments absorption shift attributed to a delocalized electric field across the thylakoid membranes [6]. For the large number of signals they observed, they provided apparently definitive interpretations, and I was rather discouraged: is there still something to discover in photosynthesis by flash absorption spectroscopy? Fortunately, that was the time when Q-switch ruby lasers became available, delivering light pulses of about $30 \mathrm{~ns}$ and permitting a much better time resolution than the microsecond flashes of Witt and Ke. With a Q-switch ruby laser, I set up an instrument with a sub-microsecond time resolution. My first results were to give a new look at a short-lived signal studied by Witt; I proposed a different interpretation in terms of triplet states of chlorophyll and of carotenoids [7]. At the same time, Britton Chance and Don De Vault also turned to the field of photosynthesis and published in 1966 important observations on cytochrome oxidation in photosynthetic bacteria [8]. 
In flash absorption spectroscopy, as applied to research in photosynthesis, reaction centers (RC) are excited with a short pulse of light. This starts a sequence of electron transfer reactions that have to be unravelled. The technique permits the identification of the chemical partners in these reactions through the (more or less specific) difference between absorption spectra of the forms present before and after the excitation flash. We can thus determine the sequence of reactions and their kinetics. Studying the effect of important parameters such as temperature, $\mathrm{pH}$, presence of inhibitors, and so on, would then allow to elucidate their mechanism. Moreover, there are a variety of RCs: photosystem 1 (PS I) and photosystem 2 (PS II) in plants, and others in several classes of photosynthetic bacteria so that there are enough questions to occupy a large number of laboratories during several decades!

In the 1970ties, additional advances were permitted by the availability of purified biological materials such as isolated RCs, and by technical advances such as picosecond lasers. In my own laboratory, we contributed mostly by studying light-induced signals in the near infra-red, between 780 and $1300 \mathrm{~nm}$. While no photosynthetic pigments in plants absorb in this region, several light-induced species do. For instance, radical-cations of the primary electron donors (P-680 and P-700 in PS II and PS I, P-870 or analogues in bacteria) display a significant absorption that allows the study of their formation and the kinetics of their re-reduction. I used these properties, with the help of several co-workers, Hélène Conjeaud and Pierre Sétif, and the essential contributions of Jaap van Best, a skilled electronician trained in Duysens's lab in Leyden, and of Klaus Brettel, arriving with a PhD obtained in Witt's lab in Berlin. We were also helped by visitors coming for a sabbatical stay, among them Ken Sauer and John Biggins, or coming with purified RCs, like Kimiyuki Satoh. We took advantage of the oncoming of two technical devices: the laser diodes emitting at $820 \mathrm{~nm}$, a wavelength perfectly adapted to our projects, and the sensitive and high-quantum efficiency, fast-response photodiodes as photodetectors, which had to be coupled to a fast-response amplifier. Our results strongly questioned a number of apparently well-established interpretations lasting from 20 year old publications by Witt's group, such as the kinetics of electron donation to P-680 in PS II and the sequence of electron acceptors in the PS I RC [9-14]. Later on, using our flash equipment in Saclay, my co-workers and myself have been involved mostly in studying parameters that govern electron transfer in purple bacteria [15-22].

As explained earlier, the technique of flash absorption spectroscopy, used by Norrish and Porter was what we now name the "pump-probe" method: the effect of a strong excitation flash (pump flash) is probed by the light from weak monitoring flashes (probe flashes) arriving before and at variable times after the excitation flash. This method has not been used later on, in the 1950's and 1960's, by researchers in the field of photosynthesis; for example, Witt and ourselves used only one (excitation) flash, the effect of which was probed by continuous monochromatic light sent through the sample. This method is straightforward but it is limited by the time resolution of the photodetector to around $1 \mathrm{~ns}$ at the best. For sub-nanosecond and picosecond time resolution, the pump-probe technique has been re-adapted, first by Peter Rentzepis at the Bell Labs [23], and then by several other laboratories (see below). The later availability of femtosecond laser pulses has permitted the following of electron transfer in RCs with a time resolution of $1 \mathrm{fs}$. The pumping of tunable dyes easily provided monitoring light at selected wavelengths. The pump-probe technique saw another important facet, in the microsecond and millisecond time domains, with an apparatus developed by Pierre Joliot [24]. Thanks to a very careful management of the probe signal, he was able to obtain an extremely high sensitivity, around $5 \times 10^{-5}$ absorbance units, even with rather turbid biological materials. Interestingly, with the development of solid-state electronics, the use of xenon flashes for pumpprobe spectroscopy is seeing a revival, as witnessed by the contribution by Hutchinson et al. in this issue [25].

In the 1970s and 1980s, many results have been obtained by flash absorption spectroscopy on photosynthetic reactions, either in organelles or in purified RCs. I shall mention a few of the most active laboratories involved although the examples are far from being a complete list.

With nanosecond set-ups, in addition to Witt and coworkers in Berlin, and to ourselves in Saclay, I should mention Bill Parson in Seattle, Les Dutton in Philadelphia, Lou Duysens and his colleagues in Leyden, and many others [26-31]. But many research groups turned to picosecond spectroscopy because the field seemed promising and more open. Among the contributors, I wish to mention Jean-Louis Martin, with Jacques Breton and Marten Vos, at ENSTA; Vlad Shuvalov in Puschino; Rienk van Grondelle in Amsterdam; Dewey Holten in St Louis; Maurice Windsor in Pullman; Alfred Holzwarth in Mülheim; Jim Allen and Neal Woodbury in Tempe, and others [32-39].

With the possibility of modifying RCs by site-directed mutations and determining their 3-D structures at the atomic level, precise questions could be raised and answered through collaborations between flash spectroscopists, molecular geneticists and X-ray crystallographers. It also became feasible to study the effect of temperature in a very broad range, or to selectively replace molecules in RCs by chemical analogues, such as quinones with different redox potentials, and to analyse the effects on the reaction kinetics. Finally, with femtosecond time resolution, it became possible to address detailed questions on the mechanism of ultrafast energy transfer within the antenna and electron transfer in the RCs $[36,40]$. 
Flash-absorption spectroscopy also proved to be very useful to study photoreactions in artificial systems mostly made of chlorophyll-like molecules and of electron donors or acceptors. To avoid a list that is too long, I mention only a few aspects of my own contributions. I first modelled triplet-triplet energy transfer from chlorophyll to carotenoids by associating the pigments in detergent micelles. I then studied the carotene radical-cation formed by electron transfer to excited thiazine dye molecules [41]. I then had a very fruitful collaboration with Devens Gust, Ana Moore and Tom Moore, from Tempe, on the photoreactions taking place in triad molecules made of a porphyrin, a carotenoid and a quinone $[42,43]$. With Jean-Pierre Sauvage, from Strasbourg, we studied the properties of a bis-porphyrin supermolecule [44].

In addition to the study of photosynthetic systems, flash absorption spectroscopy has proved very useful for elucidating practically all photobiological reactions, involving a large variety of pigments, such as rhodopsin, bacteriorhodopsin, and even phytochrome, in spite of its extremely weak concentration in whole cells (see e.g. [45]). Jean-Louis Martin and his group have carefully studied the photoreactions of carboxyhemoglobin, down to the femtosecond domain. Our laboratory contributed a little to understand the photoconversion of protochlorophyllide into chlorophyllide, but the major developments were made rather recently, under the leadership of Klaus Brettel, with the study of flavo-enzymes involved in the repair of DNA (DNA photolyases) and in blue-light signalling (cryptochromes) $([46,47]$, see also next section and other articles in this issue).

\section{Forty years at the crossroads of means and ends (by MB)}

Before being hired in Saclay in 1991, where he spent the remainder of his career, Klaus Brettel studied physics and biophysics at the universities of Stuttgart and Gießen (Germany). He obtained his PhD (1984) and "habilitation" in physical chemistry (1990) degrees for spectroscopic work on primary reactions in photosynthesis with Prof. H. T. Witt at the Max-Volmer-Institute of the Technische Universität Berlin (TUB).

During his $\mathrm{PhD}$ work, inspired by van Best \& Mathis (see above [48]), Klaus constructed a transient absorption set-up with nanosecond resolution for the detection of flashinduced absorption changes in the near infra-red $(820 \mathrm{~nm})$ where transient chlorophyll radical-cation and triplet species are observable. Together with Eberhard Schlodder, he also developed a nanosecond set-up for the detection of flashinduced absorption changes in the red wavelength range (610-710 nm). This work was initially started by Hann-Jörg Eckert [49]. Both set-ups were designed to minimize the problem of flash-induced fluorescence background to enable the analysis of the reduction kinetics of oxidized P680 in oxygen-evolving PS II complexes from Synechococcus prepared by Günther Schatz [29, 50-55]. In oxygen-evolving PS II, each flash advances the redox state of the water-splitting complex by one step. This made single flash acquisition an absolute requirement and led to the development of so-called "single flash transient absorption", with the use of a fast detection system and the never-ending struggle for obtaining a sufficient signal-to-noise ratio. Progress has also been made regarding the time resolution. A time resolution of slightly better than $1 \mathrm{~ns}$ was required to follow the charge recombination of the primary radical pair in PS II if the first quinone acceptor is reduced before the flash [56].

During a postdoc stay in Saclay (1985/86), Klaus started working on PS I together with Pierre Setif and Paul Mathis $[14,57]$.

Back at the Max-Volmer-Institute in Berlin, together with Stephan Gerken and Eberhard Schlodder, Klaus built a transient absorption setup with nanosecond resolution for detection in the near ultraviolet where the TyrZ-related absorption changes in PSII are observable $[58,59]$. This apparatus turned out useful also for the detection of quinone (A1) related absorption changes in PS I. This period also includes the collaboration with the ESR group at the Free University Berlin around Ina Sieckmann, Christian Bock, Andreas Kamlowski, Art van der Est and Dietmar Stehlik, on the nanosecond time resolution of the spin-polarized signal in the secondary radical pair of photosystem I [60-63].

The first years in Saclay, in the group of Paul Mathis, were dedicated to photosynthesis research and are described in more detail in the first part of this contribution [64-74].

In the new century, while maintaining active in photosynthesis research with Alain Boussac, Winfried Leibl and others [75-90], inspired by an idea of Paul Mathis a few years before his retirement, Klaus' centre of interest shifted towards DNA photolyases [46, 91, 92]. This ancient protein uses blue-UVA light to repair DNA damage inflicted by UVB/C exposure (main nucleobase absorption band). Here was the chance to demonstrate the universality of the skills gained in photosynthesis research, to apply transient absorption spectroscopy to a "real" enzymatic reaction. And it became better: beyond DNA repair, it turned out that photolyase also uses visible light to tune the redox state of its catalytic cofactor, FAD, and these photo-reduction reactions involve intra-protein electron transfer from a distant tryptophan residue. At the time, this so-called photo-activation reaction was thought to proceed in a single 0.5 microsecond step [93]. It was Klaus' intuition, insight, and insistence that allowed the establishment (with colleagues André Eker, Marten Vos, Martin Byrdin and initially Corinne Aubert), over the following ten years, of the involvement of several other amino acids as stepping-stones, allowing for some of 
the single steps to be as short as a few picoseconds. Investigation of the functioning of this nanowire made photolyases one of the paradigm systems for the study of intra-protein electron transfer [47, 94-100].

In the meantime, photorepair was still evading timeresolved detection, for a number of reasons, such as irreversibility of the reaction, high background absorption of the substrate, signature bands in the UV, to name but a few. The main difficulty, however, was that the existing single-shot flash photolysis setups were limited to a time resolution of a few nanoseconds, too slow for the expected ultrafast electron transfer between FAD and the damaged DNA. It was not until 2010 that Klaus Brettel had pushed the time resolution limit of single-shot flash photolysis by an order of magnitude to the required 200 picoseconds [101] that consequently allowed the direct detection of photorepair [102].

Meanwhile, ever-new members of the photolyase protein family (comprising also the structurally homologous blue light receptors of the cryptochrome group) [103], had been discovered and astonishing variations of the electron transfer ladder were found in the wake, sometimes coupled to (de)protonation steps. Together with his new co-worker Pavel Müller [104-106], Klaus continued to study them, at the beginning in collaboration with Margaret Ahmad [107-109] and later with Lars-Oliver Essen and Pascal Plaza [110-113].

But once more, as with photosynthesis several years earlier, after a basic understanding of the system, Klaus sought for new challenges. All along, the particular combination of the setups that Klaus Brettel had developed turned out to be of crucial importance for further discoveries. On the one hand, the "photorepair setup" allowed privileged access to the "nanosecond gap" (most flash photolysis setups are not fast enough to attain a resolution of one nanosecond; while most pump-probe setups have stability issues for such long delays). On the other hand, the "millisecond setup" provided for ultra-high sensitivity in the millisecond regime (better then $10^{-4}$ in quasi-single shot mode). Their combination and adaptation allowed Klaus and Martin Byrdin to be the first to detect the long sought-for triplet state of GFP-type fluorescent proteins [114] and to discover its surprisingly long lifetime (milliseconds instead of microseconds as earlier believed based on experiments with fluorescence correlation spectroscopy).

Another challenge arose upon the discovery by Fred Beisson and Damien Sorigué of a novel photo-enzyme of biotechnological relevance [115]. Indeed, the newly discovered Fatty Acid Photodecarboxylase (FAP) also harbours a flavin cofactor involved in electron and proton transfer reactions with the substrate. Klaus' expertise allowed the initiation of the elucidation of the intricate kinetic steps in this photoenzymatic reaction $[116,117]$. Thus, again the happy combination of a spectroscopist's skill and a physico-chemists insight allowed unravelling one more aspect of light-induced electron transfer.

During his years at the Service de Bioenergetique in Saclay, Klaus interacted with a constant flow of PhD students, postdocs, short- or long-time visitors and colleagues, sharing his views on the art of "photobiological physical chemistry": Marc Polm [71], Thomas Schwartz [118], Krzysztof Dobek [119], Frans van Mieghem [64, 65], Anja Krieger-Liskay, Krzysztof Gibasiewicz [85, 87-89, 120], John Golbeck [63, 66, 79, 82], Peter Faller [75, 78], Fabrice Rappaport [83, 84, 86], Corinne Aubert [46, 91, 92], Valérie Sartor [47], Rufat Agalarov [76, 80, 81], Martin Byrdin, Baldiserra Giovanni [107, 108], Sandrine Villette [96-98], Agathe Espagne [111, 112, 121, 122], Thiagarajan Viruthachalam [100-102, 122], Pavel Müller, Junpei Yamamoto [105, 110, 112, 123], Ryan Martin [105, 112, 123], Gabor Sipka [90], many of whom are today proudly contributing to this special issue (see last section). Klaus also strived to overcome the sometimes challenging barriers between "Material" and "Live" sciences, as exemplified by his collaboration with next-door "Material" spectroscopist Thomas Gustavsson.

Among the basic lessons Klaus conveyed were those to always keep an eye on the essential, to distinguish interpretation from observation and to maintain a critical view upon one's own work. Klaus always professed that Science advances best if results are discussed with equal attention to the arguments of everyone, regardless of their status or age. Another of Klaus' imperatives was to expose his thoughts and findings in a way that would allow others to reproduce his experiments and conclusions without difficulty. Plato comes to mind who, in his "Meno" dialogue, had Socrates state that to become knowledge, insight needs to be duly documented.

When we informed Klaus about this special issue, he asked whether it would be possible to reproduce a hardly accessible "early" publication where he had outlined approaches and tricks to optimize time-resolution and signal-to-noise ratio in transient absorption spectroscopy of delicate samples [124]. We are happy to announce that this paper is now freely available online and it is highly recommendable reading, not only for beginning spectroscopists. More recent developments are documented in well-known journals: the crucial novel setup with 200 ps time resolution [101], the implementation of polarized transient absorption as a method to monitor fast electron transfer between species that are chemically identical, but oriented differently [98], the introduction and characterization of the commercially available and highly stable $\left[\mathrm{Ru}(\mathrm{bpy})_{3}\right]^{2+}$ complex as a reference for amplitude and time resolution in fast and ultrafast transient absorption, that should facilitate quantitative comparison of data obtained on different set-ups/in different laboratories [101, 125, 126]. 
Beyond permanently reflecting on possible solutions to the problem he was struggling with, Klaus was also concerned with scientists' societal responsibility and the conditions under which science is made, as reflected by his longstanding involvement with the German union of democratic scientists ("Bund demokratischer Wissenschaftler:innen"), and the French movement to save the research ("Sauvons la recherche").

Over the years, Klaus has never missed an opportunity to promote Photobiology, a broad discipline that includes the various aspects of his work. As a very active member of the executive committee of the Société Française de Photobiologie, SFPb (2003-2017) and of the Scientific Advisory Board of the European Society for Photobiology (ESP, since 2011), he contributed to the scientific program of the ESP congresses and proposed outstanding speakers and symposia at the cutting-edge of our science.

\section{Legacy, tribute, continuation...}

We are happy to announce that today, this virtual volume unites 18 contributions by scientists from 17 countries (Canada, Czech republic, Finland, France, Germany, Hungary, India, Italy, Japan, Lebanon, Poland, Russia, Spain, Switzerland, Taiwan, UK, US) touching upon the wide variety of the subjects dealt with by Klaus at various times [25, 127-143].

Three papers are dedicated to photosynthetic systems [127-129]: Agostini et al. used optically detected magnetic resonance (ODMR) to study the antenna triplet states in heliobacterial reaction centers. They propose that the triplet states are localised on the cytoplasmatic side of the complex, not far apart from each other but far away from both the electron transport chain and the carotenoid bound to the complex, thus suggesting a sacrificial role for ROS protection [127]. Cherepanov et al. used ultrafast spectroscopy with $720 \mathrm{~nm}$ excitation to study PS I from Synechocystis sp. PCC 6803 with mutations around $A_{-1}$ on both branches. They found that in certain mutants the reduction of $A_{1}$ occurred with a decreased quantum yield of charge separation, correlated with a slowing of the phylloquinone reduction, but not with the initial transient spectra measured at the shortest time delay. Their results support a branch competition model [128]. Gibasiewicz et al. used nanosecond spectroscopy with $532 \mathrm{~nm}$ excitation to investigate the temperature dependence of charge recombination in mutant Rhodobacter sphaeroides reaction centers. They studied the role of protein dynamics and concluded that the modifications of the protein environment affect the overall back electron transfer kinetics primarily by changing the redox potential of the accessory bacteriochlorophyll $\mathrm{B}_{\mathrm{A}}$ and not by changing the protein relaxation dynamics [129].
The role of surprisingly slow protein dynamics is at the heart of a quasi-steady-state spectroscopic study: Rumfeldt et al. used UV-Vis absorption spectroscopy on a seconds-tohours timescale to study solvent access to the chromophore binding pocket in bacterial phytochrome from Deinococcus radiodurans [130]. They propose a model where a protein hairpin fluctuates slowly between open and closed conformations, thereby controlling the deprotonation process of the chromophore on a minute time-scale. "Slow" takes a different meaning in the context of the study by Zhuang et al. on the flavoprotein TrmFO from Thermus thermophilus [131]. The authors used ultrafast spectroscopy and MD simulations to study excited flavin lifetimes as a probe for active site dynamics. In a mutated variant, they observed that no exchange occurs between different configurations on the timescale up to at least $2 \mathrm{~ns}$, despite the presumed flexibility of the quenching residue Trp214. In a related study, a Hungarian-French-British collaboration used the same protein (along with some other flavoproteins) to establish the vibrational marker of the recently discovered tyrosine cation radical by ultrafast transient infrared spectroscopy [132].

Femtosecond Mid-IR spectroscopy is also used for the study of ultrafast proton release in photoexcited $\left(\lambda_{\mathrm{ex}}=580 \mathrm{~nm}\right)$ phycocyanobilin in methanol solution by Theiß et al. [133]. The authors observed IR absorption continua that are assigned to inter- and intramolecular H-bonded networks, allowing them to propose an extension of the existing model for phycocyanobilin excited state deactivation.

A French-German team of Klaus' long-time collaborators used ultrafast spectroscopy in the visible spectral region to explore the electron transfer chain starting from an oxidized FAD in NewPHL, a recently discovered subgroup of ancestral photolyases [134]. The authors found that an unprecedentedly fast deprotonating tryptophanyl radical (in less than $100 \mathrm{ps}$ ) cannot prevent rapid recombination and conclude that conversion of the fully oxidized FAD to the semi-quinone state should be rather difficult in vivo.

A synthetic FAD derivative ( $(\mathrm{FAD})$, which may confer an increased DNA repair efficiency, was the subject of the ultrafast spectroscopic study performed by Jacoby-Morris et al. to study the possible role of intra-FAD electron transfer for DNA repair by photolyases [135]. The authors found that the excited state flavin accepts an electron from the modified adenine in less than $10 \mathrm{ps}$ followed by rapid charge recombination. They postulate that in $\varepsilon F A D$-reconstituted DNA photolyase, the $\varepsilon$ Ade moiety acts as a real intermediate in the photoinduced electron transfer reaction.

Gindt et al. studied the oxidation of native semiquinone $\mathrm{FADH}^{\circ}$ in $V c \mathrm{CRY}-1$, a member of the cryptochrome DASH family, whose flavoproteins may use blue light both for repairing CPDs and for signal transduction [136]. The authors found both $\mathrm{pH}$ and substrate-binding-dependent 
oxidation kinetics. They used resonance Raman spectroscopy to probe for structural changes near the cofactor related to the observed changes in the rate of $\mathrm{FADH}^{\circ}$ oxidation and found that only substrate-binding seemed to induce a structural change near the FAD cofactor while the $\mathrm{pH}$ effect is ascribed to a conserved glutamate residue.

A paper from Protasova et al. investigates the mechanism of colour change in mKate2, an engineered red fluorescent protein used as popular marker in cell biology [137]. The authors found that the unsual red-to-green transformation is in fact due to a pre-existing green fraction that becomes better visible upon bleaching of the red form.

Three more papers deal with chemical model systems for light-induced electron transfer [138-140]. Gotico et al. applied microsecond-resolved transient absorption to study the proton controlled action of an imidazole a rectifying electron relay in a photoredox triad, while Maffeis et al. use picosecond resolved fluorescence on the paradigmatic push-pull dye P1. The work by Dhenadhayalan et al. combines the two techniques for the characterization of synergistic dynamics of photoionization and photoinduced electron transfer in micelles containing coumarin 450 . Gotico et al. synthesised modular complexes comprised of a $\mathrm{Ru}-$ chromophore, an imidazole electron relay function, and a terpyridine unit as coordination site for a metal ion and studied light-induced electron transfer sequences by transient absorption. They observed the transient formation of an imidazolyl radical which is clear evidence for the function of the imidazole group as an electron relay [138]. Maffeis et al. used comparative femtosecond fluorescence upconversion measurements in solution and in films to show that the P1 dye undergoes a picosecond electronic relaxation from the bright Franck-Condon (FC) state to a low-emitting chargetransfer (CT) state in a polar environment [139]. Dhenadhayalan et al. found that the photoionisation of coumarin 450 is monophotonic in nature and the yield is dependent on the charge of the micelles. The presence of various aromatic amines functioning as electron donor quenches the coumarins' photoionized state by rapid re-reduction [140].

Finally, three papers are dedicated to the study of the binding of redox-active cofactors (flavins and quinones) and how they impact protein function [141-143]. Morimoto et al. used both nanosecond molecular dynamics simulations and a repair essay on a minute timescale to assess the role of the protein in binding and functioning of the antenna cofactor 8-HDF in Xenopus (6-4) photolyase. In silico simulations indicated that a hydrophobic amino acid residue located at the entrance of the binding site dominates translocation of a loop upon binding of 8-HDF, and a mutation of this residue caused dysfunction of the efficient energy transfer in the DNA repair reaction [141]. Lafaye et al. modified the cofactor binding specificity of the engineered flavoprotein minisOG to enhance the production yield of singlet oxygen $\Phi \Delta$. They identified the R57Q mutant as a flavoprotein that selectively binds riboflavin in cellulo, with a modestly improved $\Phi \Delta$ [142]. No collection on biological electron transfer is complete without a contribution dealing with efforts to describe what happens via theoretical simulations. Here, the paper by Dhananjayan et al. analyses the binding of the quinone in respiratory complex I from $T$. thermophiles (and other organisms). Touching upon three of the main themes of this special issue (protein dynamics, role of cofactors, electron transfer), this work highlights the importance of soft mode protein motions for quinone entrance into the enzyme's narrow binding site and the ensuing possible functional role for quinone reduction by the terminal ironsulfur cluster [143].

We are especially happy to conclude the collection with a paper dedicated to the construction and testing of a new kind of transient absorption spectrometer that aims at obtaining wavelength-resolved microsecond kinetics in the visible spectral region [25]. Interestingly, the design mirrors that of the original Norrish/Porter pump-probe principle, only adapted to today's technological possibilities. It thus appears that Norrish and Porter are the fathers and grandfathers of an unexpected large and diverse family.

Acknowledgements $\mathrm{MB}$ wants to thank the staff at Bulletin de la Société Royale des Sciences de Liège for making available online the full text of reference [124], Eberhard Schlodder for very helpful advice as well as him and Klaus Brettel for introducing me to the art (« details matter ») of Flash photolysis.

\section{References}

1. Norrish, R. G. W., \& Porter, G. (1949). Chemical reactions produced by very high light intensities. Nature, 164, 658-658. https://doi.org/10.1038/164658a0

2. Norrish, R. G. W., Porter, G., \& Thrush, B. A. (1953). Studies of the explosive combustion of hydrocarbons by kinetic spectroscopy I. Free radical absorption spectra in acetylene combustion. Proceedings of Royal Society of London Series, Mathematical and Physical Sciences, 216, 165-183. https://doi.org/10.1098/ rspa.1953.0014

3. Witt, H. T., Moraw, R., \& Müller, A. (1959). Blitzlichtphotometrie. Zeitschrift für Physikalische Chemie, 20, 193-205. https://doi.org/10.1524/zpch.1959.20.3_4.193

4. Ke, B., Treharne, R. W., \& McKibben, C. (1964). Flashing-light spectrophotometer for studying the fast reactions occurring during photosynthesis. Review of Scientific Instruments, 35, 296300. https://doi.org/10.1063/1.1718808

5. Witt, H. T. (1971). Coupling of quanta, electrons, fields, ions and phosphorylation in the functional membrane of photosynthesis. Results by pulse spectroscopic methods. Quarterly Reviews of Biophysics, 4, 365-477. https://doi.org/10.1017/S003358350 0000834

6. Schliephake, W., Junge, W., \& Witt, H. T. (1968). Correlation between field formation, proton translocation, and the light reactions in photosynthesis. Zeitschrift für Naturforschung. Teil B, 23, 1571-1578. https://doi.org/10.1515/znb-1968-1203 
7. Mathis, P. (1966). Variation d'absorption de courte durée induite dans une suspension de chloroplastes par un éclair laser. Comptes Rendus Hebdomadaires Des Seances De L Academie Des Sciences Serie D, 263, 1770-1772.

8. De Vault, D., \& Chance, B. (1966). Studies of photosynthesis using a pulsed laser: I. Temperature dependence of cytochrome oxidation rate in chromatium. Evidence for tunneling. Biophysics Journal, 6, 825-847. https://doi.org/10.1016/S0006-3495(66) 86698-5

9. Van Best, J. A., \& Mathis, P. (1978). Kinetics of reduction of the oxidized primary electron donor of photosystem II in spinach chloroplasts and in chlorella cells in the microsecond and nanosecond time ranges following flash excitation. Biochimica Biophysica Acta BBA-Bioenergetics, 503, 178-188. https://doi. org/10.1016/0005-2728(78)90170-6

10. Conjeaud, H., Mathis, P., \& Paillotin, G. (1979). Primary and secondary electron donors in photosystem II of chloroplasts. Rates of electron transfer and location in the membrane. Biochimica Biophysica Acta BBA-Bioenergetics, 546, 280-291. https://doi.org/10.1016/0005-2728(79)90046-X

11. Takahashi, Y., Hansson, Ö., Mathis, P., \& Satoh, K. (1987). Primary radical pair in the photosystem II reaction centre. Biochimica Biophysica Acta BBA-Bioenergetics, 893, 49-59. https://doi. org/10.1016/0005-2728(87)90147-2

12. Mathis, P., Sauer, K., \& Remy, R. (1978). Rapidly reversible flash-induced electron transfer in a P-700 chlorophyll-protein complex isolated with SDS. FEBS Letters, 88, 275-278. https:// doi.org/10.1016/0014-5793(78)80192-6

13. Mathis, P., \& Setif, P. (1981). Near infra-red absorption spectra of the chlorophyll a cations and triplet state in vitro and in vivo. Israel Journal of Chemistry, 21, 316-320.

14. Brettel, K., Setif, P., \& Mathis, P. (1986). Flash-induced absorption changes in photosystem-I at low-temperature-evidence that the electron acceptor-a1 is vitamin-K1. FEBS Letters, 203, 220-224. https://doi.org/10.1016/0014-5793(86)80746-3

15. Mathis, P., Sinning, I., \& Michel, H. (1992). Kinetics of electron transfer from the primary to the secondary quinone in rhodopseudomonas viridis. Biochimica Biophysica Acta BBA-Bioenergetics, 1098, 151-158. https://doi.org/10.1016/S0005-2728(05) 80330-5

16. Ortega, J. M., \& Mathis, P. (1993). Electron transfer from the tetraheme cytochrome to the special pair in isolated reaction centers of Rhodopseudomonas viridis. Biochemistry, 32, 1141-1151.

17. Wachtveitl, J., Farchaus, J. W., Mathis, P., \& Oesterhelt, D. (1993). Tyrosine 162 of the photosynthetic reaction center L-subunit plays a critical role in the cytochrome $\mathrm{c} 2$ mediated rereduction of the photooxidized bacteriochlorophyll dimer in Rhodobacter sphaeroides. 2. Quantitative kinetic analysis. Biochemistry, 32, 10894-10904.

18. Venturoli, G., Mallardi, A., \& Mathis, P. (1993). Electron transfer from cytochrome $\mathrm{c} 2$ to the primary donor of Rhodobacter sphaeroides reaction centers. A temperature dependence study. Biochemistry, 32, 13245-13253.

19. Lin, X., Williams, J. C., Allen, J. P., \& Mathis, P. (1994). Relationship between rate and free energy difference for electron transfer from cytochrome $\mathrm{c} 2$ to the reaction center in Rhodobacter sphaeroides. Biochemistry, 33, 13517-13523.

20. Dohse, B., Mathis, P., Wachtveitl, J., Laussermair, E., Iwata, S., Michel, H., \& Oesterhelt, D. (1995). Electron transfer from the tetraheme cytochrome to the special pair in the Rhodopseudomonas viridis reaction center: Effect of mutations of tyrosine L162. Biochemistry, 34, 11335-11343.

21. Drepper, F., \& Mathis, P. (1997). Structure and function of cytochrome c 2 in electron transfer complexes with the photosynthetic reaction center of Rhodobacter sphaeroides: Optical linear dichroism and EPR. Biochemistry, 36, 1428-1440.
22. Chen, I.-P., Mathis, P., Koepke, J., \& Michel, H. (2000). Uphill electron transfer in the tetraheme cytochrome subunit of the Rhodopseudomonas viridis photosynthetic reaction center: Evidence from site-directed mutagenesis. Biochemistry, 39, 3592-3602.

23. Leigh, J. S., Netzel, T. L., Dutton, P. L., \& Rentzepis, P. M. (1974). Primary events in photosynthesis: PICOSECOND kinetics of carotenoid bandshifts in Rhodopseudomonas spheroides chromatophores. FEBS Letters, 48, 136-140. https://doi.org/10. 1016/0014-5793(74)81081-1

24. Joliot, P., Beal, D., \& Frilley, B. (1980). Une nouvelle méthode spectrophotométrique destinée à l'étude des réactions photosynthétiques. Journal de Chimie Physique, 77, 209-216. https://doi. org/10.1051/jcp/1980770209

25. Hutchison, C., Chukhutsina, V., Parker, S., \& van Thor, J. J. (2021). Open hardware microsecond transient absorption spectrometer for linear response. Photochemistry and Photobiological Sciences. https://doi.org/10.1007/s43630-021-00127-6

26. Parson, W. W., Clayton, R. K., \& Cogdell, R. J. (1975). Excited states of photosynthetic reaction centers at low redox potentials. Biochimica Biophysica Acta BBA-Bioenergetics, 387, 265-278. https://doi.org/10.1016/0005-2728(75)90109-7

27. Schenck, C. C., Blankenship, R. E., \& Parson, W. W. (1982). Radical-pair decay kinetics, triplet yields and delayed fluorescence from bacterial reaction centers. Biochimica Biophysica Acta BBA-Bioenergetics, 680, 44-59. https://doi.org/10.1016/ 0005-2728(82)90315-2

28. Chidsey, C. E. D., Kirmaier, C., Holten, D., \& Boxer, S. G. (1984). Magnetic field dependence of radical-pair decay kinetics and molecular triplet quantum yield in quinone-depleted reaction centers. Biochimica Biophysica Acta BBA-Bioenergetics, 766, 424-437. https://doi.org/10.1016/0005-2728(84)90258-5

29. Schlodder, E., Brettel, K., Schatz, G., \& Witt, H. (1984). Analysis of the Chl-a-Ii+ reduction kinetics with nanosecond time resolution in oxygen-evolving photosystem-II particles from synechococcus at 680 and $824 \mathrm{Nm}$. Biochimica et Biophysica Acta, 765, 178-185. https://doi.org/10.1016/0005-2728(84)90012-4

30. Gunner, M. R., Robertson, D. E., \& Dutton, P. L. (1986). Kinetic studies on the reaction center protein from Rhodopseudomonas sphaeroides: The temperature and free energy dependence of electron transfer between various quinones in the QA site and the oxidized bacteriochlorophyll dimer. Journal of Physical Chemistry, 90, 3783-3795. https://doi.org/10.1021/j100407a054

31. Danielius, R. V., Satoh, K., van Kan, P. J. M., Plijter, J. J., Nuijs, A. M., \& van Gorkom, H. J. (1987). The primary reaction of photosystem II in the D1-D2-cytochrome b-559 complex. FEBS Letters, 213, 241-244.

32. Shuvalov, V. A., Klevanik, A. V., Sharkov, A. V., Matveetz, Ju. A., \& Krukov, P. G. (1978). Picosecond detection of BChl-800 as an intermediate electron carrier between selectively-excited P870 and bacteriopheophytin in Rhodospirillum rubrum relaction centers. FEBS Letters, 91, 135-139. https://doi.org/10.1016/ 0014-5793(78)80034-9

33. Holten, D., Hoganson, C., Windsor, M. W., Schenck, C. C., Parson, W. W., Migus, A., Fork, R. L., \& Shank, C. V. (1980). Subpicosecond and picosecond studies of electron transfer intermediates in Rhodopseudomonas sphaeroides reaction centers. Biochimica Biophysica Acta BBA-Bioenergetics, 592, 461-477. https://doi.org/10.1016/0005-2728(80)90092-4

34. Kirmaier, C., Holten, D., \& Parson, W. W. (1985). Temperature and detection-wavelength dependence of the picosecond electron-transfer kinetics measured in Rhodopseudomonas sphaeroides reaction centers. Resolution of new spectral and kinetic components in the primary charge-separation process. Biochimica Biophysica Acta BBA-Bioenergetics, 810, 33-48. https://doi.org/10.1016/0005-2728(85)90204-X 
35. Woodbury, N. W., Becker, M., Middendorf, D., \& Parson, W. W. (1985). Picosecond kinetics of the initial photochemical electron-transfer reaction in bacterial photosynthetic reaction centers. Biochemistry, 24, 7516-7521. https://doi.org/10.1021/ bi00347a002

36. Breton, J., Martin, J.-L., Migus, A., Antonetti, A., \& Orszag, A. (1986). Femtosecond spectroscopy of excitation energy transfer and initial charge separation in the reaction center of the photosynthetic bacterium Rhodopseudomonas viridis. Proceedings National Academy of Science USA, 83, 5121-5125.

37. Schatz, G. H., Brock, H., \& Holzwarth, A. R. (1987). Picosecond kinetics of fluorescence and absorbance changes in photosystem II particles excited at low photon density. Proceedings National Academy of Science USA, 84, 8414-8418. https://doi. org/10.1073/pnas.84.23.8414

38. Lin, S., Jaschke, P. R., Wang, H., Paddock, M., Tufts, A., Allen, J. P., Rosell, F. I., Mauk, A. G., Woodbury, N. W., \& Beatty, J. T. (2009). Electron transfer in the Rhodobacter sphaeroides reaction center assembled with zinc bacteriochlorophyll. Proceedings of the National Academy of Sciences USA, 106, 8537-8542. https://doi.org/10.1073/pnas.0812719106

39. Rockley, M. G., Windsor, M. W., Cogdell, R. J., \& Parson, W. W. (1975). Picosecond detection of an intermediate in the photochemical reaction of bacterial photosynthesis. Proceedings of the National Academy of Sciences USA, 72, 2251-2255. https://doi.org/10.1073/pnas.72.6.2251

40. Fleming, G. R. (2018). The contributions of 49ers to the measurements and models of ultrafast photosynthetic energy transfer. Photosynthesis Research, 135, 3-8. https://doi.org/10. 1007/s11120-017-0360-4

41. Mathis, P., \& Vermeglio, A. (1972). Formes transitoires des carotenoides: Etat triplet et radical-cation. Photochemistry and Photobiology, 15, 157-164.

42. Moore, T. A., Gust, D., Mathis, P., Mialocq, J.-C., Chachaty, C., Bensasson, R. V., Land, E. J., Doizi, D., Liddell, P. A., \& Lehman, W. R. (1984). Photodriven charge separation in a carotenoporphyrin-quinone triad. Nature, 307, 630-632.

43. Gust, D., Moore, T. A., Bensasson, R. V., Mathis, P., Land, E. J., Chachaty, C., Moore, A. L., Liddell, P. A., \& Nemeth, G. A. (1985). Stereodynamics of intramolecular triplet energy transfer in carotenoporphyrins. Journal of the American Chemical Society, 107, 3631-3640.

44. Chardon-Noblat, S., Sauvage, J.-P., \& Mathis, P. (1989). Efficient photoinduced intramolecular energy transfer in an oblique bis-porphyrin system. Angewandte Chemie (International ed. in English), 28, 593-595.

45. Giraud, E., Zappa, S., Vuillet, L., Adriano, J.-M., Hannibal, L., Fardoux, J., Berthomieu, C., Bouyer, P., Pignol, D., \& Verméglio, A. (2005). A new type of bacteriophytochrome acts in tandem with a classical bacteriophytochrome to control the antennae synthesis in Rhodopseudomonas palustris. Journal of Biological Chemistry, 280, 32389-32397. https://doi.org/ 10.1074/jbc.M506890200

46. Aubert, C., Vos, M. H., Mathis, P., Eker, A. P. M., \& Brettel, K. (2000). Intraprotein radical transfer during photoactivation of DNA photolyase. Nature, 405, 586-590. https://doi.org/10. $1038 / 35014644$

47. Byrdin, M., Sartor, V., Eker, A. P. M., Vos, M. H., Aubert, C., Brettel, K., \& Mathis, P. (2004). Intraprotein electron transfer and proton dynamics during photoactivation of DNA photolyase from E-coli: Review and new insights from an "inverse" deuterium isotope effect. Biochimica et Biophysica Acta-Bioenergetics, 1655, 64-70. https://doi.org/10.1016/j.bbabio.2003. 07.001

48. Van Best, J. A., \& Mathis, P. (1978). Apparatus for the measurement of small absorption change kinetics at $820 \mathrm{~nm}$ in the nanosecond range after a ruby laser flash. Review of Scientific Instruments, 49, 1332-1335. https://doi.org/10.1063/1.1135579

49. Eckert, H.-J., Renger, G., \& Witt, H. T. (1984). Reduction kinetics of the photo-oxidized chlorophyll a+II in the nanosecond range: Measurements of the absorption changes at $688 \mathrm{~nm}$ under repetitive flash excitation. FEBS Letters, 167, 316-320. https:// doi.org/10.1016/0014-5793(84)80149-0

50. Brettel, K., \& Witt, H. (1983). Reduction kinetics of the photooxidized chlorophyll-alpha-II in chloroplasts measured in the nanosecond range at $837 \mathrm{~nm}$ under repetitive flash excitation. Photobiochemistry and Photobiophysics, 6, 253-260.

51. Akerlund, H., Brettel, K., \& Witt, H. (1984). Reversible alteration of nanosecond reduction of chlorophyll-aii(+) in inside-out thylakoids correlated to inhibition and reconstitution of oxygenevolving activity. Biochimica et Biophysica Acta, 765, 7-11. https://doi.org/10.1016/0005-2728(84)90150-6

52. Brettel, K., Schlodder, E., \& Witt, H. (1984). Nanosecond reduction kinetics of photooxidized chlorophyll-alpha-ii (p-680) in single flashes as a probe for the electron pathway, H+-release and charge accumulation in the O-2-evolving complex. Biochimica et Biophysica Acta, 766, 403-415. https://doi.org/10.1016/00052728(84)90256-1

53. Brettel, K., Ford, R., Schlodder, E., Atkinson, Y., Witt, H., \& Evans, M. (1985). Rapid electron-transfer reactions associated with oxygen evolution in photosystem-II preparations from spinach and phormidium-laminosum. FEBS Letters, 181, 88-94. https://doi.org/10.1016/0014-5793(85)81119-4

54. Schlodder, E., Brettel, K., \& Witt, H. (1985). Relation between microsecond reduction kinetics of photooxidized chlorophyllAII (p-680) and photosynthetic water oxidation. Biochimica et Biophysica Acta, 808, 123-131. https://doi.org/10.1016/00052728(85)90034-9

55. Brettel, K., Schlodder, E., \& Witt, H. (1985). Evidence for only one stable electron-acceptor in the reaction center of photosystem-II in spinach-chloroplasts-analysis by double flash experiments with nanosecond time resolution. Photobiochemistry and Photobiophysics, 9, 205-213.

56. Schlodder, E., \& Brettel, K. (1988). Primary charge separation in closed photosystem-II with a lifetime of 11-Ns-flash-absorption spectroscopy with O-2-evolving photosystem-II complexes from synechococcus. Biochimica et Biophysica Acta, 933, 22-34. https://doi.org/10.1016/0005-2728(88)90052-7

57. Brettel, K., \& Setif, P. (1987). Magnetic-field effects on primary reactions in photosystem-I. Biochimica et Biophysica Acta, 893 , 109-114. https://doi.org/10.1016/0005-2728(87)90030-2

58. Gerken, S., Brettel, K., Schlodder, E., \& Witt, H. (1988). Optical characterization of the immediate electron-donor to chlorophyllAiit in O-2-evolving photosystem-ii complexes - tyrosine as possible electron carrier between chlorophyll-aii and the wateroxidizing manganese complex. FEBS Letters, 237, 69-75. https:// doi.org/10.1016/0014-5793(88)80174-1

59. Gerken, S., Brettel, K., Schlodder, E., \& Witt, H. (1987). Direct observation of the immediate electron-donor to chlorophyll-A+ii (p-680+) in oxygen-evolving photosystem-ii complexes - resolution of nanosecond kinetics in the Uv. FEBS Letters, 223, 376-380. https://doi.org/10.1016/0014-5793(87)80322-8

60. Bock, C., Vanderest, A., Brettel, K., \& Stehlik, D. (1989). Nanosecond electron-transfer kinetics in photosystem-I as obtained from transient epr at room-temperature. FEBS Letters, 247, 91-96. https://doi.org/10.1016/0014-5793(89)81247-5

61. Brettel, K., Sieckmann, I., Fromme, P., Vanderest, A., \& Stehlik, D. (1992). Low-temperature epr on single-crystals of photosystem-I-study of the iron-sulfur center Fa. Biochimica et Biophysica Acta, 1098, 266-270. https://doi.org/10.1016/S00052728(05)80346-9 
62. Sieckmann, I., Brettel, K., Bock, C., Vanderest, A., \& Stehlik, D. (1993). Transient Electron-Paramagnetic-Resonance Of The Triplet-State of $\mathrm{P}(700)$ in Photosystem. 1. Evidence for triplet delocalization at room-temperature. Biochemistry, 32, 48424847. https://doi.org/10.1021/bi00069a020

63. Vanderest, A., Bock, C., Golbeck, J., Brettel, K., Setif, P., \& Stehlik, D. (1994). Electron-transfer from the acceptor a(1) to the iron-sulfur centers in photosystem-i as studied by transient epr spectroscopy. Biochemistry, 33, 11789-11797. https://doi. org/10.1021/bi00205a015

64. Hillmann, B., Brettel, K., Vanmieghem, F., Kamlowski, A., Rutherford, A., \& Schlodder, E. (1995). Charge Recombination Reactions In Photosystem-Ii.2. Transient absorbency difference spectra and their temperature-dependence. Biochemistry, 34, 4814-4827. https://doi.org/10.1021/bi00014a039

65. Vanmieghem, F., Brettel, K., Hillmann, B., Kamlowski, A., Rutherford, A., \& Schlodder, E. (1995). Charge recombination reactions in photosystem-Ii.1. Yields, recombination pathways, and kinetics of the primary pair. Biochemistry, 34, 4798-4813. https://doi.org/10.1021/bi00014a038

66. Brettel, K., \& Golbeck, J. H. (1995). Spectral and kinetic characterization of electron acceptor A(1) in a photosystem I core devoid of iron-sulfur centers F-X, F-B and F-A. Photosynthesis Research, 45, 183-193. https://doi.org/10.1007/BF00015559

67. Brettel, K. (1996). Hypothesis on low temperature effects in photosystem I (PS I). Prog Biophys Mol Biol, 65, 321.

68. Brettel, K. (1997). Electron transfer and arrangement of the redox cofactors in photosystem I. Biochimica Biophysica Acta-Bioenergetics, 1318, 322-373. https://doi.org/10.1016/S0005-2728(96) 00112-0

69. Redding, K., MacMillan, F., Leibl, W., Brettel, K., Hanley, J., Rutherford, A. W., Breton, J., \& Rochaix, J. D. (1998). A systematic survey of conserved histidines in the core subunits of photosystem I by site-directed mutagenesis reveals the likely axial ligands of P-700. EMBO Journal, 17, 50-60. https://doi. org/10.1093/emboj/17.1.50

70. Brettel, K., Leibl, W., \& Liebl, U. (1998). Electron transfer in the heliobacterial reaction center: Evidence against a quinone-type electron acceptor functioning analogous to $\mathrm{A}(1)$ in photosystem I. Biochimica Biophysica Acta-Bioenergetics, 1363, 175-181. https://doi.org/10.1016/S0005-2728(98)00010-3

71. Polm, M., \& Brettel, K. (1998). Secondary pair charge recombination in photosystem I under strongly reducing conditions: Temperature dependence and suggested mechanism. Biophysical Journal, 74, 3173-3181. https://doi.org/10.1016/S0006-3495(98) 78023-3

72. Schlodder, E., Falkenberg, K., Gergeleit, M., \& Brettel, K. (1998). Temperature dependence of forward and reverse electron transfer from $\mathrm{A}(1)(-)$, the reduced secondary electron acceptor in photosystem I. Biochemistry, 37, 9466-9476. https://doi.org/ 10.1021/bi973182r

73. Brettel, K., \& Vos, M. H. (1999). Spectroscopic resolution of the picosecond reduction kinetics of the secondary electron acceptor A(1) in photosystem I. FEBS Letters, 447, 315-317. https://doi. org/10.1016/S0014-5793(99)00317-8

74. Kusumoto, N., Setif, P., Brettel, K., Seo, D., \& Sakurai, H. (1999). Electron transfer kinetics in purified reaction centers from the green sulfur bacterium chlorobium tepidum studied by multiple-flash excitation. Biochemistry, 38, 12124-12137. https://doi.org/10.1021/bi990452s

75. Faller, P., Boussac, A., Debus, R. J., Brettel, K., \& Rutherford, A. W. (2001). Tyrosyl radicals in photosystem II: The stable tyrosyl $\mathrm{D}$ and the catalytic tyrosyl Z. Journal of Inorganic Biochemistry, $86,214-214$.
76. Boudreaux, B., MacMillan, F., Teutloff, C., Agalarov, R., Gu, F. F., Grimaldi, S., Bittl, R., Brettel, K., \& Redding, K. (2001). Mutations in both sides of the photosystem I reaction center identify the phylloquinone observed by electron paramagnetic resonance spectroscopy. Journal of Biological Chemistry, 276, 37299-37306. https://doi.org/10.1074/jbc.M102327200

77. Brettel, K., \& Leibl, W. (2001). Electron transfer in photosystem I. Biochimica Biophysica Acta-Bioenergetics, 1507, 100-114. https://doi.org/10.1016/S0005-2728(01)00202-X

78. Faller, P., Debus, R. J., Brettel, K., Sugiura, M., Rutherford, A. W., \& Boussac, A. (2001). Rapid formation of the stable tyrosyl radical in photosystem II. Proceedings of National Academy of Sciences USA, 98, 14368-14373. https://doi.org/10.1073/pnas. 251382598

79. Shen, G. Z., Antonkine, M. L., van der Est, A., Vassiliev, I. R., Brettel, K., Bittl, R., Zech, S. G., Zhao, J. D., Stehlik, D., Bryant, D. A., \& Golbeck, J. H. (2002). Assembly of photosystem I. II. Rubredoxin is required for the in vivo assembly of $\mathrm{F}-\mathrm{x}$ in synechococcus sp PCC 7002 as shown by optical and EPR spectroscopy. Journal of Biological Chemistry, 277, 20355-20366. https://doi.org/10.1074/jbc.M201104200

80. Agalarov, R., \& Brettel, K. (2003). Temperature dependence of biphasic forward electron transfer from the phylloquinone(s) $\mathrm{A}(1)$ in photosystem I: Only the slower phase is activated. Biochimica Biophysica Acta-Bioenergetics, 1604, 7-12. https://doi. org/10.1016/S0005-2728(03)00024-0

81. Gong, X. M., Agalarov, R., Brettel, K., \& Carmeli, C. (2003). Control of electron transport in photosystem I by the iron-sulfur cluster F-X in response to intra- and intersubunit interactions. Journal of Biological Chemistry, 278, 19141-19150. https://doi. org/10.1074/jbc.M301808200

82. Xu, W., Chitnis, P. R., Valieva, A., van der Est, A., Brettel, K., Guergova-Kuras, M., Pushkar, Y. N., Zech, S. G., Stehlik, D., Shen, G. Z., Zybailov, B., \& Golbeck, J. H. (2003). Electron transfer in cyanobacterial photosystem I-II. Determination of forward electron transfer rates of site-directed mutants in a putative electron transfer pathway from $\mathrm{A}(0)$ through $\mathrm{A}(1)$ to $\mathrm{F}-\mathrm{x}$. Journal of Biological Chemistry, 278, 27876-27887. https://doi. org/10.1074/jbc.M302965200

83. Sugiura, M., Rappaport, F., Brettel, K., Noguchi, T., Rutherford, A. W., \& Boussac, A. (2004). Site-directed mutagenesis of the Thermosynechococcus elongatus photosystem II: The O-2-evolving enzyme lacking the redox-active tyrosine D. Biochemistry, 43, 13549-13563. https://doi.org/10.1021/bi048732h

84. Sugiura, M., Rappaport, F., Brettel, K., Noguchi, T., Rutherford, A. W., \& Boussac, A. (2005). Site-directed mutagenesis of Thermosynechococcus elongatus photosystem II: The O-2 evolving enzyme lacking the redox active tyrosine D. Plant and Cell Physiology, 46, S26-S26.

85. Gibasiewicz, K., Pajzderska, M., Potter, J. A., Fyfe, P. K., Dobek, A., Brettel, K., \& Jones, M. R. (2011). Mechanism of recombination of the $\mathrm{P}+\mathrm{HA}$ - radical pair in mutant rhodobacter sphaeroides reaction centers with modified free energy gaps between $\mathrm{P}+\mathrm{BA}$ and P+HA-. The Journal of Physical Chemistry B, 115, 1303713050. https://doi.org/10.1021/jp206462g

86. Boussac, A., Rappaport, F., Brettel, K., \& Sugiura, M. (2013). Charge recombination in S(n)TyrZ(center dot)Q(A)(-center dot) radical pairs in D1 Protein Variants Of Photosystem II: long range electron transfer in the marcus inverted region. The Journal of Physical Chemistry B, 117, 3308-3314. https://doi.org/10. 1021/jp400337j

87. Gibasiewicz, K., Pajzderska, M., Dobek, A., Brettel, K., \& Jones, M. R. (2013). Analysis of the kinetics of P+HA- recombination in membrane-embedded wild-type and mutant rhodobacter sphaeroides reaction centers between 298 and $77 \mathrm{k}$ indicates that 
the adjacent negatively charged $\mathrm{Q}(\mathrm{A})$ ubiquinone modulates the free energy of P+HA- and may influence the rate of the protein dielectric response. The Journal of Physical Chemistry B, 117, 11112-11123. https://doi.org/10.1021/jp4011235

88. Gibasiewicz, K., Pajzderska, M., Dobek, A., Karolczak, J., Burdzinski, G., Brettel, K., \& Jones, M. R. (2013). Analysis of the temperature-dependence of $\mathrm{P}+\mathrm{HA}$ - charge recombination in the Rhodobacter sphaeroides reaction center suggests nanosecond temperature-independent protein relaxation. Physical Chemistry Chemical Physics: PCCP, 15, 16321-16333. https://doi.org/ $10.1039 / \mathrm{c} 3 \mathrm{cp} 44187 \mathrm{c}$

89. Gibasiewicz, K., Bialek, R., Pajzderska, M., Karolczak, J., Burdzinski, G., Jones, M. R., \& Brettel, K. (2016). Weak temperature dependence of $\mathrm{P}(+) \mathrm{H}(\mathrm{A})(-)$ recombination in mutant Rhodobacter sphaeroides reaction centers. Photosynthesis Research, 128, 243-258. https://doi.org/10.1007/s11120-016-0239-9

90. Sipka, G., Müller, P., Brettel, K., Magyar, M., Kovacs, L., Zhu, Q., Xiao, Y., Han, G., Lambrev, P. H., Shen, J.-R., \& Garab, G. (2019). Redox transients of P680 associated with the incremental chlorophyll-a fluorescence yield rises elicited by a series of saturating flashes in diuron-treated photosystem II core complex of Thermosynechococcus vulcanus. Physiologia Plantarum, 166, 22-32. https://doi.org/10.1111/ppl.12945

91. Aubert, C., Brettel, K., Mathis, P., Eker, A. P. M., \& Boussac, A. (1999). EPR detection of the transient tyrosyl radical in DNA photolyase from Anacystis nidulans. Journal of the American Chemical Society, 121, 8659-8660. https://doi.org/10.1021/ja991 $938 \mathrm{z}$

92. Aubert, C., Mathis, P., Eker, A. P. M., \& Brettel, K. (1999). Intraprotein electron transfer between tyrosine and tryptophan in DNA photolyase from Anacystis nidulans. Proceedings of National Academy Sciences USA, 96, 5423-5427. https://doi. org/10.1073/pnas.96.10.5423

93. Heelis, P. F., Okamura, T., \& Sancar, A. (1990). Excited-state properties of Escherichia coli DNA photolyase in the picosecond to millisecond time scale. Biochemistry, 29, 5694-5698.

94. Byrdin, M., Eker, A. P. M., Vos, M. H., \& Brettel, K. (2003). Dissection of the triple tryptophan electron transfer chain in Escherichial coli DNA photolyase: Trp382 is the primary donor in photoactivation. Proceedings of National Academy Sciences USA, 100, 8676-8681. https://doi.org/10.1073/pnas.1531645100

95. Pan, J., Byrdin, M., Aubert, C., Eker, A. P. M., Brettel, K., \& Vos, M. H. (2004). Excited-state properties of flavin radicals in flavoproteins: Femtosecond spectroscopy of DNA photolyase, glucose oxidase, and flavodoxin. The Journal of Physical Chemistry B, 108, 10160-10167. https://doi.org/10.1021/jp037837b

96. Lukacs, A., Eker, A. P. M., Byrdin, M., Villette, S., Pan, J., Brettel, K., \& Vos, M. H. (2006). Role of the middle residue in the triple tryptophan electron transfer chain of DNA photolyase: Ultrafast spectroscopy of a Trp -> Phe mutant. The Journal of Physical Chemistry B, 110, 15654-15658. https://doi.org/10. 1021/jp063686b

97. Byrdin, M., Villette, S., Eker, A. P. M., \& Brettel, K. (2007). Observation of an intermediate tryptophanyl radical in W306F mutant DNA photolyase from Escherichia coli supports electron hopping along the triple tryptophan chain. Biochemistry, 46, 10072-10077. https://doi.org/10.1021/bi700891f

98. Byrdin, M., Villette, S., Espagne, A., Eker, A. P. M., \& Brettel, K. (2008). Polarized transient absorption to resolve electron transfer between tryptophans in DNA photolyase. The Journal of Physical Chemistry B, 112, 6866-6871. https://doi.org/10.1021/ jp711435y

99. Lukacs, A., Eker, A. P. M., Byrdin, M., Brettel, K., \& Vos, M. H. (2008). Electron hopping through the 15 angstrom triple tryptophan molecular wire in DNA photolyase occurs within 30 ps.
Journal of the American Chemical Society, 130, 14394. https:// doi.org/10.1021/ja805261m

100. Byrdin, M., Lukacs, A., Thiagarajan, V., Eker, A. P. M., Brettel, K., \& Vos, M. H. (2010). Quantum yield measurements of shortlived photoactivation intermediates in DNA photolyase: toward a detailed understanding of the triple tryptophan electron transfer chain. Journal of Physical Chemistry A, 114, 3207-3214. https:// doi.org/10.1021/jp9093589

101. Byrdin, M., Thiagarajan, V., Villette, S., Espagne, A., \& Brettel, K. (2009). Use of ruthenium dyes for subnanosecond detector fidelity testing in real time transient absorption. Review of Scientific Instruments, 80, 043102. https://doi.org/10.1063/1.31172 08

102. Thiagarajan, V., Byrdin, M., Eker, A. P. M., Müller, P., \& Brettel, K. (2011). Kinetics of cyclobutane thymine dimer splitting by DNA photolyase directly monitored in the UV. Proceedings of National Academy Sciences USA, 108, 9402-9407. https://doi. org/10.1073/pnas.1101026108

103. Chaves, I., Pokorny, R., Byrdin, M., Hoang, N., Ritz, T., Brettel, K., Essen, L.-O., van der Horst, G. T. J., Batschauer, A., \& Ahmad, M. (2011). The cryptochromes: blue light photoreceptors in plants and animals. In S. S. Merchant, W. R. Briggs, $\&$ D. Ort (Eds.), Annual review of plant biology (Vol. 62, pp. 335-364). Santa Clara: Palo Alto.

104. Müller, P., Brettel, K., Grama, L., Nyitrai, M., \& Lukacs, A. (2016). Photochemistry of wild-type and N378D mutant E-coli DNA photolyase with oxidized FAD cofactor studied by transient absorption spectroscopy. ChemPhysChem, 17, 1329-1340. https://doi.org/10.1002/cphc.201501077

105. Müller, P., Yamamoto, J., Martin, R., Iwai, S., \& Brettel, K. (2015). Discovery and functional analysis of a 4th electrontransferring tryptophan conserved exclusively in animal cryptochromes and (6-4) photolyases. Chemical Communications, 51, 15502-15505. https://doi.org/10.1039/c5cc06276d

106. Müller, P., Bouly, J.-P., Hitomi, K., Balland, V., Getzoff, E. D., Ritz, T., \& Brettel, K. (2014). ATP binding turns plant cryptochrome into an efficient natural photoswitch. Science and Reports, 4, 5175. https://doi.org/10.1038/srep05175

107. Giovani, B., Byrdin, M., Ahmad, M., \& Brettel, K. (2003). Lightinduced electron transfer in a cryptochrome blue-light photoreceptor. Natural Structural Biology, 10, 489-490. https://doi.org/ $10.1038 / \mathrm{nsb} 933$

108. Zeugner, A., Byrdin, M., Bouly, J. P., Bakrim, N., Giovani, B., Brettel, K., \& Ahmad, M. (2005). Light-induced electron transfer in Arabidopsis cryptochrome-1 correlates with in vivo function. Journal of Biological Chemistry, 280, 19437-19440. https://doi. org/10.1074/jbc.C500077200

109. Balland, V., Byrdin, M., Eker, A. P. M., Ahmad, M., \& Brettel, K. (2009). What makes the difference between a cryptochrome and DNA photolyase? A spectroelectrochemical comparison of the Flavin redox transitions. Journal of American Chemical Society, 131, 426. https://doi.org/10.1021/ja806540j

110. Yamamoto, J., Plaza, P., \& Brettel, K. (2017). Repair of (6-4) lesions in DNA by (6-4) photolyase: 20 years of quest for the photoreaction mechanism. Photochemistry and Photobiology, 93, 51-66. https://doi.org/10.1111/php.12696

111. Lacombat, F., Espagne, A., Dozova, N., Plaza, P., Müller, P., Brettel, K., Franz-Badur, S., \& Essen, L.-O. (2019). Ultrafast oxidation of a tyrosine by proton-coupled electron transfer promotes light activation of an animal-like cryptochrome. Journal of the American Chemical Society, 141, 13394-13409. https:// doi.org/10.1021/jacs.9b03680

112. Martin, R., Lacombat, F., Espagne, A., Dozova, N., Plaza, P., Yamamoto, J., Müller, P., Brettel, K., \& de la Lande, A. (2017). Ultrafast flavin photoreduction in an oxidized animal (6-4) photolyase through an unconventional tryptophan tetrad. Physical 
Chemistry Chemical Physics: PCCP, 19, 24493-24504. https:// doi.org/10.1039/c7cp04555g

113. Müller, P., Ignatz, E., Kiontke, S., Brettel, K., \& Essen, L.-O. (2018). Sub-nanosecond tryptophan radical deprotonation mediated by a protein-bound water cluster in class II DNA photolyases. Chemical Science, 9, 1200-1212. https://doi.org/ $10.1039 / \mathrm{c} 7 \mathrm{sc} 03969 \mathrm{~g}$

114. Byrdin, M., Duan, C., Bourgeois, D., \& Brettel, K. (2018). A long-lived triplet state is the entrance gateway to oxidative photochemistry in green fluorescent proteins. Journal of the American Chemical Society, 140, 2897-2905. https://doi.org/ $10.1021 /$ jacs.7b12755

115. Sorigué, D., Légeret, B., Cuiné, S., Morales, P., Mirabella, B., Guédeney, G., Li-Beisson, Y., Jetter, R., Peltier, G., \& Beisson, F. (2016). Microalgae synthesize hydrocarbons from longchain fatty acids via a light-dependent pathway. Plant Physiology, 171, 2393-2405. https://doi.org/10.1104/pp.16.00462

116. Sorigue, D., Legeret, B., Cuine, S., Blangy, S., Moulin, S., Billon, E., Richaud, P., Brugiere, S., Coute, Y., Nurizzo, D., Müller, P., Brettel, K., Pignol, D., Arnoux, P., Li-Beisson, Y., Peltier, G., \& Beisson, F. (2017). An algal photoenzyme converts fatty acids to hydrocarbons. Science, 357, 903-907. https://doi.org/10.1126/science.aan6349

117. Sorigué, D., Hadjidemetriou, K., Blangy, S., Gotthard, G., Bonvalet, A., Coquelle, N., Samire, P., Aleksandrov, A., Antonucci, L., Benachir, A., Boutet, S., Byrdin, M., Cammarata, M., Carbajo, S., Cuiné, S., Doak, R. B., Foucar, L., Gorel, A., Grünbein, M., ... Beisson, F. (2021). Mechanism and dynamics of fatty acid photodecarboxylase. Science. https://doi.org/10. 1126/science.abd5687

118. Schwartz, T., \& Brettel, K. (1995). Search for the presence and role of a second phylloquinone in the core of photosystem I. In P. Mathis (Ed.), Photosynthesis: from light to biosphere proceedings of the Xth international photosynthesis congress. Dordrecht: Kluwer Academic Publications.

119. Dobek, K., \& Brettel, K. (2004). Red absorption changes accompanying electron transfer from $\mathrm{A} 1$ to the iron-sulfur clusters in photosystem I. In A. van der Est (Ed.), Photosynthesis: fundamental aspects to global perspectives: proceedings of the 13th international congress of photosynthesis montreal (pp. 40-42). Oak Park: Alliance Communications Group.

120. Gibasiewicz, K., Brettel, K., Dobek, A., \& Leibl, W. (1999). Re-examination of primary radical pair recombination in Rp. viridis with $\mathrm{Q}(\mathrm{A})$ reduced. Chemical Physics Letters, 315, 95-102. https://doi.org/10.1016/S0009-2614(99)01158-6

121. Espagne, A., Byrdin, M., Eker, A. P. M., \& Brettel, K. (2009). Very fast product release and catalytic turnover of DNA photolyase. ChemBioChem, 10, 1777-1780. https://doi.org/10. 1002/cbic. 200900328

122. Thiagarajan, V., Villette, S., Espagne, A., Eker, A. P. M., Brettel, K., \& Byrdin, M. (2010). DNA repair by photolyase: a novel substrate with low background absorption around 265 $\mathrm{nm}$ for transient absorption studies in the UV. Biochemistry, 49, 297-303. https://doi.org/10.1021/bi901562a

123. Yamamoto, J., Martin, R., Iwai, S., Plaza, P., \& Brettel, K. (2013). Repair of the (6-4) photoproduct by DNA photolyase requires two photons. Angewandte Chemie International Edition, 52, 7432-7436. https://doi.org/10.1002/anie.201301567

124. Brettel, K. (1996). Flash absorption spectroscopy. Principles and applications in plant photosynthesis research. Bull Société R Sci Liège, 65, 262-268. https://popups.uliege.be/0037-9565/ index.php?id $=9871$

125. Brettel, K., \& Schlodder, E. (1988). Ru(bipy)3cl2 luminescence as optical step signal for detector testing. Review of Scientific Instruments, 59, 670-671. https://doi.org/10.1063/1. 1139809
126. Müller, P., \& Brettel, K. (2012). [Ru(bpy)(3)](2+) as a reference in transient absorption spectroscopy: Differential absorption coefficients for formation of the long-lived (MLCT)-M-3 excited state. Photochemical \& Photobiological Sciences, 11, 632-636. https://doi.org/10.1039/c2pp05333k

127. Agostini, A., Bortolus, M., Ferlez, B., Walters, K., Golbeck, J. H., van der Est, A., \& Carbonera, D. (2021). Differential sensitivity to oxygen among the bacteriochlorophylls $g$ in the type-I reaction centers of Heliobacterium modesticaldum. Photochemical \& Photobiological Sciences, 20,747-759. https://doi.org/10. 1007/s43630-021-00049-3

128. Cherepanov, D. A., Shelaev, I. V., Gostev, F. E., Nadtochenko, V. A., Xu, W., Golbeck, J. H., \& Semenov, AYu. (2021). Symmetry breaking in photosystem I: ultrafast optical studies of variants near the accessory chlorophylls in the A- and B-branches of electron transfer cofactors. Photochemical \& Photobiological Sciences, 20, 1209-1227. https://doi.org/10.1007/10.1007/ s43630-021-00094-y

129. Gibasiewicz, K., Pajzderska, M., Białek, R., \& Jones, M. R. (2021). Temperature dependence of nanosecond charge recombination in mutant Rhodobacter sphaeroides reaction centers: Modelling of the protein dynamics. Photochemical \& Photobiological Sciences, 20, 913-922. https://doi.org/10.1007/ s43630-021-00069-z

130. Rumfeldt, J., Kurttila, M., Takala, H., \& Ihalainen, J. A. (2021). The hairpin extension controls solvent access to the chromophore binding pocket in a bacterial phytochrome-a UV-Vis absorption spectroscopy study. Photochemical \& Photobiological Sciences, 20, 1173-1181. https://doi.org/10.1007/s43630-021-00090-2

131. Zhuang, B., Nag, L., Sournia, P., Croitoru, A., Ramodiharilafy, R., Lambry, J.-C., Myllykallio, H., Aleksandrov, A., Liebl, U., \& Vos, M. H. (2021). Photochemical processes in flavo-enzymes as a probe for active site dynamics: TrmFO of Thermus thermophilus. Photochemical \& Photobiological Sciences, 20, 663-670. https://doi.org/10.1007/s43630-021-00052-8

132. Pirisi, K., Nag, L., Fekete, Z., Iuliano, J. N., Tolentino Collado, J., Clark, I. P., Pécsi, I., Sournia, P., Liebl, U., Greetham, G. M., Tonge, P. J., Meech, S. R., Vos, M. H., \& Lukacs, A. (2021). Identification of the vibrational marker of tyrosine cation radical using ultrafast transient infrared spectroscopy of flavoprotein systems. Photochemical \& Photobiological Sciences, 20, 369-378. https://doi.org/10.1007/s43630-021-00024-y

133. Theiß, M., Grupe, M., Lamparter, T., Mroginski, M. A., \& Diller, R. (2021). Ultrafast proton release reaction and primary photochemistry of phycocyanobilin in solution observed with fstime-resolved mid-IR and UV/Vis spectroscopy. Photochemical \& Photobiological Sciences, 20, 715-732. https://doi.org/10. 1007/s43630-021-00045-7

134. Lacombat, F., Espagne, A., Dozova, N., Plaza, P., Müller, P., Emmerich, H.-J., Saft, M., \& Essen, L.-O. (2021). Ultrafast photoreduction dynamics of a new class of CPD photolyases. Photochemical \& Photobiological Sciences, 20, 733-746. https:// doi.org/10.1007/s43630-021-00048-4

135. Jacoby-Morris, K., Barnard, D. T., Narayanan, M., Byrne, M., McBride, R. A., Singh, V. R., Stanley, R. J. (2021) Ultrafast excited state dynamics of flavin 1,n6-ethenoadenine dinucleotide: Implications for the electron transfer mechanism in $\varepsilon F A D$ reconstituted DNA photolyase. Photochemistry and Photobiological Sciences. https://doi.org/10.1007/s43630-022-00187-2

136. Gindt, Y. M., Connolly, G., Vonder Haar, A. L., Kikhwa, M., \& Schelvis, J. P. M. (2021). Investigation of the $\mathrm{pH}$-dependence of the oxidation of FAD in VcCRY-1, a member of the cryptochrome-DASH family. Photochemical \& Photobiological Sciences, 20, 831-841. https://doi.org/10.1007/s43630-021-00063-5

137. Protasova, E. A., Mishin, A. S., Lukyanov, K. A., Maksimov, E. G., \& Bogdanov, A. M. (2021). Chromophore reduction plus 
reversible photobleaching: How the mKate2 "photoconversion" works. Photochemical \& Photobiological Sciences, 20, 791-803. https://doi.org/10.1007/s43630-021-00060-8

138. Gotico, P., Herrero, C., Protti, S., Quaranta, A., Sheth, S., Fallahpour, R., et al. (2021). Proton-controlled Action of an Imidazole as Electron Relay in a Photoredox Triad. Photochemistry and Photobiological Sciences. https://doi.org/10.1007/ s43630-021-00163-2.

139. Maffeis, V., Jousselme, B., \& Gustavsson, T. (2021). Hole injection from P1 dye hot-excited states in p-type dye sensitized films: A fluorescence study. Photochemical \& Photobiological Sciences, 20, 1257-1271. https://doi.org/10.1007/ s43630-021-00098-8

140. Dhenadhayalan, N., Shaji, V. S. A., Selvaraju, C., \& Thiagarajan, V. (2021). Synergistic dynamics of photoionization and photoinduced electron transfer probed by laser flash photolysis and ultrafast fluorescence spectroscopy. Photochemical \&
Photobiological Sciences, 20, 1109-1124. https://doi.org/10. 1007/s43630-021-00084-0

141. Morimoto, A., Hosokawa, Y., Miyamoto, H., Verma, R. K., Iwai, S., Sato, R., \& Yamamoto, J. (2021). Key interactions with deazariboflavin cofactor for light-driven energy transfer in Xenopus (6-4) photolyase. Photochemical \& Photobiological Sciences, 20, 875-887. https://doi.org/10.1007/s43630-021-00065-3

142. Lafaye, C., Aumonier, S., Torra, J., Signor, L., von Stetten, D., Noirclerc-Savoye, M., et al. (2021). Riboflavin-binding proteins for singlet oxygen production. Photochemistry and Photobiological Sciences. https://doi.org/10.1007/s43630-021-00156-1.

143. Dhananjayan, N., Wang, P., Leontyev, I., \& Stuchebrukhov, A. A. (2021). Quinone binding in respiratory complex I: going through the eye of a needle. The squeeze-in mechanism of passing the narrow entrance of the quinone site. Photochemistry and Photobiological Sciences. https://doi.org/10.1007/s43630-021-00113-y 